Engineering

Manuscript Number: MINE-D-18-00661R1

Title: Separation of tungsten and cobalt from WC-Co hard metal wastes using ion-exchange and solvent extraction with ionic liquid

Article Type: Research Paper

Keywords: Ion exchange; Ionic liquid; Solvent extraction; Tungsten; WC-Co hard metal

Corresponding Author: Dr. Masahiko Matsumiya, Dr.

Corresponding Author's Institution: Yokohama National University

First Author: Yueqi Song

Order of Authors: Yueqi Song; Yusuke Tsuchida; Masahiko Matsumiya, Dr.; Yuuki Uchino; Itaru Yanagi

Abstract: Recently, the development of a process to separate $W$ and Co from tungsten carbide-cobalt (WC-Co) hard metal wastes has become important. In this study, we proposed a novel hydrometallurgical process involving the following steps: pretreatment, leaching, ion exchange, and two-step solvent extraction (I) and (II) using ionic liquids (ILS). First, an AlCrN film coating was completely removed from a wC-Co hard metal sample by leaching in a H2SO4-H3PO4 mixed acid medium at $423 \mathrm{~K}$ for $120 \mathrm{~h}$. Then, the sample was oxidized at $1173 \mathrm{~K}$ for $10 \mathrm{~h}$ and XRD analysis showed that WO3 and CoWO4 were generated during this oxidization. After the oxidization, the leaching reaction WO3 $+2 \mathrm{LiOH} \rightarrow \mathrm{WO} 42-+2 \mathrm{Li}++\mathrm{H} 2 \mathrm{O}$ smoothly proceeded in leaching solution of $0.1 \mathrm{~mol} / \mathrm{L} \mathrm{LiOH}$ at $343 \mathrm{~K}$ for 19 $\mathrm{h}$ and the stoichiometry of WO3:LiOH was 1:2, which was consistent with that of the leaching reaction. Further, after the leaching step was completed, it was beneficial to exchange $\mathrm{H}+$ and Lit in the leaching solution using a cation exchange resin.

Solvent extraction was performed using triethyl-n-pentyl phosphonium bis (trifluoromethylsulfonyl) amide as the IL, and tri-n-octylamine was employed as the extractant for the selective separation of W(VI) for solvent extraction (I). The extraction percentages (E) of W(VI) and Co(II) were $>95 \%$ and $<2.5 \%$ at $\mathrm{pH}=1.0$, respectively, and the selective extraction of $W(V I)$ was confirmed in this study. The extraction mechanism of $W(V I)$ was based on the ion association reaction $n[R 3 N]$ org + $[\mathrm{HxWyOzn}-] \mathrm{aq}+\mathrm{n}[\mathrm{H}+] \mathrm{aq} \Leftrightarrow[(\mathrm{R} 3 \mathrm{NH}) \mathrm{nHxWyOz}]$ org. In solvent extraction (II), a PC-88A/[P2225][NTf2] system was used for the effective extraction of Co(II) at $\mathrm{pH}>4.3$. The slope analysis results showed that the extraction mechanism was governed by the cation exchange reaction $[\mathrm{Co} 2+] \mathrm{aq}+2[(\mathrm{HL}) 2]$ org $\Leftrightarrow[\mathrm{CoL} 2 \cdot 2 \mathrm{HL}]$ org $+2[\mathrm{H}+] \mathrm{aq}$. A series of novel hydrometallurgical process using IL enabled us to demonstrate that W(VI) and Co(II) were efficiently recovered from WC-Co hard metal wastes. 
Dear Prof. B. A. Wills

Editor of Minerals Engineering

Thank you for sending e-mail and many valuable reviewer comments.

The comments for each reviewer about the revised manuscript were written as follows.

We hope that the revised manuscript will be suitable for the publication.

Sincerely yours.

Dr. Masahiko Matsumiya

Graduate School of Environment and Information Sciences, Yokohama National University 79-2 Tokiwadai, Hodogaya-ku, Yokohama, 240-8501, JAPAN

E-mail address: matsumiya-masahiko-dh@ynu.ac.jp

Tel \& Fax: +81-45-339-3464 


\section{For Reviewer 1}

Thank you for sending many useful comments.

According to your comments, the revised manuscript was corrected as follows.

Reviewer \#1: This article is about the separation of tungsten and cobalt from WC-Co hard metal wastes using ion-exchange and solvent extraction with ionic liquid. This research presents interesting results. It merits to be published in Minerals Engineering if the authors clarify the following points.

1. The structure figure and preparation of IL should be given.

According to your suggestion, the structure figure of IL was added in new Fig. 2 in the revised manuscript.

The preparation of IL was also added in the revised manuscript. (p.5L20-L25)

2. Error bars should be given in the figures

According to your suggestion, the error bar was added in new Fig. 7 in the revised manuscript.

3. IR spectra may be used to study the extraction mechanism

Based your suggestion, we tried to measure IR spectrum for aqueous and organic phases to study the extraction mechanism. However, we did not obtain the effective results from IR spectrum. Therefore, we tried to measure UV-Vis spectrum for aqueous and organic phases. As a result, we found that it was better to confirm the W(VI) complex state of aqueous and organic phases from UV-Vis analysis. The UV-Vis result was added in new Fig.9. The experimental condition and the related comments were also added in the revised manuscript. (p.6L3-L6, p.9L22-L27)

4. The unit of M should be revised to be $\mathrm{mol} / \mathrm{l}$

According to your suggestion, the unit of $\mathrm{M}$ was modified to be mol/L in the revised manuscript.

5. Why equation 10 is called as an anion exchange process? It is an ion association extraction mechanism.

According to your suggestion, the name of the exchange process was modified in the revised manuscript. (p.2L17, p.9L12, p.11L18)

6. The stripping and recycling of IL-based extraction system should be investigated.

Based on your suggestion, we additionally investigated the stripping and recycling of IL-based extraction system at fifth cycles. The stripping and recycling results were added in new Table 4 in the revised manuscript. The experimental condition and the related comments were also added in the revised manuscript. (p.3L25-L26, p.6L23-p.7L26, p.10L20-p.11L3)

The other revised sentences were marked with red letter in the revised manuscript.

We hope that the revised manuscript will be suitable for the publication. 
Dr. Masahiko Matsumiya

Graduate School of Environment and Information Sciences, Yokohama National University 79-2 Tokiwadai, Hodogaya-ku, Yokohama, 240-8501, JAPAN

E-mail address: matsumiya-masahiko-dh@ynu.ac.jp

Tel \& Fax: +81-45-339-3464 


\section{Highlights}

- A novel hydrometallurgical process was consisted of two step solvent extraction using ionic liquid.

- W(VI) was selectively extracted from WC-Co hard metal by $\left[\mathrm{R}_{3} \mathrm{~N}\right] /\left[\mathrm{P}_{2225}\right]\left[\mathrm{NTf}_{2}\right], \mathrm{R}=\left(\mathrm{CH}_{2}\right)_{7} \mathrm{CH}_{3}$.

- The extraction mechanism of $\mathrm{W}(\mathrm{VI})$ was based on the ion association reaction.

- $\mathrm{Co}(\mathrm{II})$ was effectively extracted by $\mathrm{PC}-88 \mathrm{~A} /\left[\mathrm{P}_{2225}\right]\left[\mathrm{NTf}_{2}\right]$ at $\mathrm{pH}>4.3$ after removal of W(VI).

- $\left[\mathrm{R}_{3} \mathrm{~N}\right] /\left[\mathrm{P}_{2225}\right]\left[\mathrm{NTf}_{2}\right]$ solvent was repeatedly applied on extraction-stripping process at $5^{\text {th }}$ cycles. 
using ion-exchange and solvent extraction with ionic liquid

\section{Yueqi SONG ${ }^{\mathrm{a}}$, Yusuke TSUCHIDA ${ }^{\mathrm{a}}$, Masahiko MATSUMIYA ${ }^{\mathrm{a}}$,} Yuuki, UCHINO ${ }^{\mathrm{b}}$, and Itaru YANAGI ${ }^{\mathrm{b}}$

${ }^{a}$ Graduate School of Environment and Information Sciences, Yokohama National University, 79-2 Tokiwadai, Hodogaya-ku, Yokohama 240-8501, Japan.

${ }^{\mathrm{b}}$ Sanwayuka Industrial Corporation, 15 Fukada, Ichiriyama-cho, Kariya-shi, Aichi 448-0002, Japan.

*Corresponding author E-mail address: matsumiya-masahiko-dh@ynu.ac.jp Tel \& Fax:+81-45-339-3464 


\begin{abstract}
Recently, the development of a process to separate $\mathrm{W}$ and Co from tungsten carbide-cobalt (WC-Co) hard metal wastes has become important. In this study, we proposed a novel hydrometallurgical process involving the following steps: pretreatment, leaching, ion exchange, and two-step solvent extraction (I) and (II) using ionic liquids (ILs). First, an AlCrN film coating was completely removed from a WC-Co hard metal sample by leaching in a $\mathrm{H}_{2} \mathrm{SO}_{4}-\mathrm{H}_{3} \mathrm{PO}_{4}$ mixed acid medium at $423 \mathrm{~K}$ for $120 \mathrm{~h}$. Then, the sample was oxidized at $1173 \mathrm{~K}$ for $10 \mathrm{~h}$ and XRD analysis showed that $\mathrm{WO}_{3}$ and $\mathrm{CoWO}_{4}$ were generated during this oxidization. After the oxidization, the leaching reaction $\mathrm{WO}_{3}+2 \mathrm{LiOH} \rightarrow \mathrm{WO}_{4}{ }^{2-}+2 \mathrm{Li}^{+}+\mathrm{H}_{2} \mathrm{O}$ smoothly proceeded in leaching solution of $0.1 \mathrm{~mol} / \mathrm{L} \mathrm{LiOH}$ at $343 \mathrm{~K}$ for $19 \mathrm{~h}$ and the stoichiometry of $\mathrm{WO}_{3}: \mathrm{LiOH}$ was $1: 2$, which was consistent with that of the leaching reaction. Further, after the leaching step was completed, it was beneficial to exchange $\mathrm{H}^{+}$and $\mathrm{Li}^{+}$in the leaching solution using a cation exchange resin.

Solvent extraction was performed using triethyl- $n$-pentyl phosphonium bis(trifluoromethylsulfonyl)amide as the IL, and tri- $n$-octylamine was employed as the extractant for the selective separation of $\mathrm{W}(\mathrm{VI})$ for solvent extraction (I). The extraction percentages $(E)$ of $\mathrm{W}(\mathrm{VI})$ and $\mathrm{Co}(\mathrm{II})$ were $>95 \%$ and $<2.5 \%$ at $\mathrm{pH}=1.0$, respectively, and the selective extraction of $\mathrm{W}(\mathrm{VI})$ was confirmed in this study. The extraction mechanism of $\mathrm{W}(\mathrm{VI})$ was based on the ion association reaction $n\left[\mathrm{R}_{3} \mathrm{~N}\right]_{\text {org }}+\left[\mathrm{H}_{x} \mathrm{~W}_{y} \mathrm{O}_{z}{ }^{n-}\right]_{\mathrm{aq}}+n\left[\mathrm{H}^{+}\right]_{\mathrm{aq}} \Leftrightarrow\left[\left(\mathrm{R}_{3} \mathrm{NH}\right)_{n} \mathrm{H}_{x} \mathrm{~W}_{y} \mathrm{O}_{z}\right]_{\text {org. }}$. In solvent extraction (II), a PC-88A/[ $\left.\mathrm{P}_{2225}\right]\left[\mathrm{NTf}_{2}\right]$ system was used for the effective extraction of $\mathrm{Co}(\mathrm{II})$ at $\mathrm{pH}$ > 4.3. The slope analysis results showed that the extraction mechanism was governed by the cation exchange reaction $\left[\mathrm{Co}^{2+}\right]_{\mathrm{aq}}+2\left[(\mathrm{HL})_{2}\right]_{\mathrm{org}} \Leftrightarrow\left[\mathrm{CoL}_{2} \cdot 2 \mathrm{HL}\right]_{\mathrm{org}}+2\left[\mathrm{H}^{+}\right]_{\mathrm{aq}}$. A series of novel hydrometallurgical process using IL enabled us to demonstrate that $\mathrm{W}(\mathrm{VI})$ and $\mathrm{Co}(\mathrm{II})$ were efficiently recovered from WC-Co hard metal wastes.
\end{abstract}

Key words: Ion exchange; Ionic liquid; Solvent extraction; Tungsten; WC-Co hard metal 


\section{Introduction}

Tungsten carbide-cobalt (WC-Co) hard metal or cemented carbide is a composite material usually comprising WC particles embedded within a Co binder. This hard metal is commonly used for manufacturing tools because of its good mechanical strength and wear resistance (Brookes, 1996). The Co content in WC-Co hard metal machining tools is usually between 4 and 12 wt\%. Because of the harmful environmental effects, each component of the hard metal must be separated. Some hydrometallurgical methods to selectively recover $\mathrm{W}$ or Co from WC-Co scraps and to process WC-Co scraps to obtain W metal or ammonium paratungstate have been proposed (Gaur, 2009).

Solvent extraction is a very useful technique to recover tungsten from its leachates (Lassner, 1995, Pandey et. al., 2001). Aliphatic amines have been widely employed as extractants (Carvalho et. al., 1991, Coca et. al., 1990, Palant et. al., 1998, Sato et. al., 1995), and tertiary amines (Gerhardt et. al., 2001) have been most frequently reported in literature. The concentration of the extractant must be low (<10 vol.\%) to avoid emulsification (Zhang et. al., 1996). Kerosene is widely employed as a diluent; however, the presence of phase modifiers is usually necessary because amino tungstate complexes are not very soluble in the organic phase. Recently, numerous studies aimed at the development of a solvent-based separation process have been conducted. In the present study, in a departure from the conventional solvent extraction approach, we investigated the feasibility of using a phosphonium ionic liquid (IL) as the medium for the separation of $\mathrm{W}$ from the leaching solution. A well-known amine with the molecular formula $\left(\mathrm{R}_{3} \mathrm{~N}, \mathrm{R}=\left(\mathrm{CH}_{2}\right)_{7} \mathrm{CH}_{3}\right)$, tri- $n$-octylamine (TOA), was chosen as the preferred extractant because it offers many advantages such as negligible solubility in the aqueous phase, high boiling point, low density, low cost, and easy availability (Lide, 1993).

The objective of this study is to develop a novel hydrometallurgical process to separate W(VI) and $\mathrm{Co}(\mathrm{II})$ from each other and from WC-Co hard metal, as shown in Fig. 1; this process involves the following steps: pretreatment, leaching, ion exchange, and two-step solvent extraction (I and II) using ILs. Moreover, the reuse of $\left[\mathrm{R}_{3} \mathrm{~N}\right] / \mathrm{IL}, \mathrm{R}=\left(\mathrm{CH}_{2}\right)_{7} \mathrm{CH}_{3}$ solvent was evaluated by solvent extraction and stripping process at $5^{\text {th }}$ cycles. 


\section{Experimental}

\subsection{Pretreatment}

The rectangular WC-Co hard metal wastes $(12 \mathrm{~mm} \times 12 \mathrm{~mm} \times 4.76 \mathrm{~mm})$ were used as a sample in this study. An AlCrN film was coated on the surface of a WC-Co sample, because its resistance to wear and oxidation during cutting extended the design life of cutting tools. This AlCrN film coating was undesirable for the complete oxidization of the WC-Co sample at high temperature, which generates $\mathrm{WO}_{3}$ and $\mathrm{CoWO}_{4}$, because it made the sample highly resistant to oxidation even at $1173 \mathrm{~K}$ (Chim et. al., 2009, Gu et. al., 2012). The WC-Co sample with AlCrN film coating was introduced in a Teflon beaker including a $\mathrm{H}_{2} \mathrm{SO}_{4}-\mathrm{H}_{3} \mathrm{PO}_{4}\left(\mathrm{H}_{2} \mathrm{SO}_{4}: \mathrm{H}_{3} \mathrm{PO}_{4}=1: 1\right)$ mixed acid solution. The leaching mixed acid solution was rotated at rates up to $300 \mathrm{rpm}$ at $423 \mathrm{~K}$ for $120 \mathrm{~h}$. After the removal of AlCrN film, the WC-Co sample was cleaned in a distilled water. The surface morphology and composition of the AlCrN film coating and WC-Co sample were analyzed by scanning electron microscopy/energy dispersive X-ray spectrometry (SEM/EDX, JSM-6510LA, JEOL Ltd.). Then, the WC-Co fragments obtained after removal of the AlCrN film coating were heated to $1173 \mathrm{~K}$ at $5 \mathrm{~K} \mathrm{~min}^{-1}$ in an oxygen atmosphere for $10 \mathrm{~h}$. The oxygen flow rate was 150 $\mathrm{mL} \mathrm{s}^{-1}$. The oxidized WC-Co sample was then pulverized to particles with a diameter of approximately $3 \mu \mathrm{m}$ using a planetary ball mill.

\subsection{Leaching}

The $0.1 \mathrm{~mol} / \mathrm{L} \mathrm{LiOH}$ solution was selected to dissolve $\mathrm{W}$ present in the oxidized WC-Co sample. The $10.0 \mathrm{~g}$ of the oxidized WC-Co powder was added to $500 \mathrm{~mL}$ of $0.1 \mathrm{~mol} / \mathrm{L} \mathrm{LiOH}$ solution. The leaching solution was then agitated at rates up to $500 \mathrm{rpm}$ at $343 \mathrm{~K}$ for $19 \mathrm{~h}$. After $\mathrm{W}$ dissolution, the solutions were passed through a 1- $\mu \mathrm{m}$-pore membrane filter to screen the undissolved oxidized residue. The concentration of $\mathrm{W}(\mathrm{VI})$ in the leaching solution was measured by inductively coupled plasma atomic emission spectroscopy (ICP-AES, ICPE-9000, Shimadzu Co.). The changes in $\mathrm{pH}$ with elapsed leaching time was precisely measured by a high-precision digital $\mathrm{pH}$ 
meter (MM-43X, DKK-TOA Corp.). The measured $\mathrm{pH}$ in the saturated leaching solution was 7.55.

\subsection{Ion exchange}

After leaching, exchange of $\mathrm{H}^{+}$and $\mathrm{Li}^{+}$in the leaching solution was performed, as the following solvent extraction was performed under acidic conditions to protonate the extractant. The ion exchange reaction of the cation exchange resin (IR120B, ORGANO Corp.) can be expressed as follows:

$$
\mathrm{R}-\mathrm{SO}_{3} \mathrm{H}+\mathrm{Li}^{+} \rightarrow \mathrm{R}-\mathrm{SO}_{3} \mathrm{Li}+\mathrm{H}^{+}
$$

According to this reaction, the amount of ions exchanged was controlled by the time of ion exchange for the constant initial amount of the cation exchange resin. The decreasing amount of $\mathrm{Li}^{+}$in the leaching solution was confirmed from the changes in $\mathrm{pH}$. Several sample solutions $\mathrm{pH}$ values of 7.55-1.0 were prepared by the ion exchange reaction.

\subsection{Solvent extraction}

In this study, the solvent extraction process consisted of two steps to effectively separate W(VI) and $\mathrm{Co}$ (II) from the leaching solution. For the solvent extraction processes (I) and (II), TOA (Wako Pure Chemical Industries, Ltd., >98.0\%) and PC-88A (DAIHACHI Chemical Industry Co. Ltd.) were selected as the extractants, respectively. The IL triethyl- $n$-pentyl phosphonium bis(trifluoromethyl-sulfonyl)amide $\left(\left[\mathrm{P}_{2225}\right]\left[\mathrm{NTf}_{2}\right]\right)$ as shown in Fig. 2 was synthesized from the metathesis reaction of $\left[\mathrm{P}_{2225}\right] \mathrm{Br}$ (Nippon Chemical Industrial Co., Ltd.,>99.5\%) with $\mathrm{Li}\left[\mathrm{NTf}_{2}\right]$ (Kanto Chemical Co., Inc., 99.7\%) in distilled water at 343 K (Tsunashima et. al., 2007, Tsunashima et. al., 2011). The synthesized $\left[\mathrm{P}_{2225}\right]\left[\mathrm{NTf}_{2}\right]$ was purified by stirring with distilled water to remove lithium and bromide ions, followed by evaporation at $423 \mathrm{~K}$ for $24 \mathrm{~h}$. The obtained $\left[\mathrm{P}_{2225}\right]\left[\mathrm{NTf}_{2}\right]$ was then dried under high vacuum $<-0.1 \mathrm{MPa}$ at $393 \mathrm{~K}$ for $48 \mathrm{~h}$. The $\left[\mathrm{P}_{2225}\right]\left[\mathrm{NTf}_{2}\right]$ and kerosene were used as the diluent for both stages. For solvent extraction (I), the aqueous phase after the ion 
exchange reaction acted as the solution. The concentration of $\left[\mathrm{H}_{x} \mathrm{~W}_{y} \mathrm{O}_{z}{ }^{n-}\right]$ and $\mathrm{Co}^{2+}$ in the 0.1 $\mathrm{mol} / \mathrm{L} \mathrm{LiOH}$ solution was $4.7 \times 10^{-2} \mathrm{~mol} / \mathrm{L}$ and $8.5 \times 10^{-3} \mathrm{~mol} / \mathrm{L}$, respectively. The TOA concentration in the organic phase was $1.0 \mathrm{~mol} / \mathrm{L}$. The $\mathrm{pH}$ of the aqueous solution was varied from 1.0 to 6.8 to investigate the extraction behavior. In order to confirm the complex state of $\mathrm{W}(\mathrm{VI})$, the absorption spectrum of $\mathrm{W}(\mathrm{VI})$ in aqueous and organic phases was measured by UV-Vis spectrometer (Perkin Elmer, Lambda750). In this spectroscopic measurement, a quartz cell with $1.0 \mathrm{~cm}$ optical path length was used in the wavelength region of 200-1000 nm.

For solvent extraction (II), the solution after the removal of $\mathrm{W}(\mathrm{VI})$ complexes using TOA acted as the aqueous phase. The concentration of PC-88A was $0.1 \mathrm{~mol} / \mathrm{L}$ in the $\mathrm{PC}-88 \mathrm{~A} /\left[\mathrm{P}_{2225}\right]\left[\mathrm{NTf}_{2}\right]$ extraction system. For the stoichiometry-related slope analysis, the $\mathrm{pH}$ of the aqueous phase was varied from 2.0 to 4.4 . All extraction processes were performed at $298 \mathrm{~K}$ with an aqueous to organic phase ratio of 1:1 by volume. The solutions were placed in a sampling tube and shaken for 5 min using a direct mixer. The concentrations of the metal ions in the aqueous phase before and after the equilibration were measured by ICP-AES. The concentration of the metal ions in the organic phase after the equilibration was calculated using a mass balance equation. The distribution ratio $(D)$ and extraction efficiency $(E)$ were defined as follows:

$$
\begin{gathered}
D=\frac{[\mathrm{M}]_{\mathrm{aq}, \mathrm{i}}[\mathrm{M}]_{\mathrm{aq}, \mathrm{f}}}{[\mathrm{M}]_{\mathrm{aq}, \mathrm{f}}} \\
E(\%)=\frac{[\mathrm{M}]_{\mathrm{aq}, \mathrm{i}}-[\mathrm{M}]_{\mathrm{aq}, \mathrm{f}}}{[\mathrm{M}]_{\mathrm{aq}, \mathrm{i}}} \times 100
\end{gathered}
$$

where $[\mathrm{M}]_{\mathrm{i}}$ and $[\mathrm{M}]_{\mathrm{f}}$ represent the initial and final concentrations of the metal ions in the aqueous phase, respectively, and the subscript aq denotes the aqueous phase.

In order to evaluate the reuse of $\left[\mathrm{R}_{3} \mathrm{~N}\right] /\left[\mathrm{P}_{2225}\right]\left[\mathrm{NTf}_{2}\right], \mathrm{R}=\left(\mathrm{CH}_{2}\right)_{7} \mathrm{CH}_{3}$ solvent system, a recycling run consisting of solvent extraction and stripping for $5^{\text {th }}$ cycles was performed. For solvent extraction, $1.0 \times 10^{3} \mathrm{mg} \mathrm{L}^{-1} \mathrm{~W}(\mathrm{VI})$ was used as the aqueous phase. The volume ratio $(\mathrm{A} / \mathrm{O})$ of the aqueous and organic phase was maintained at $\mathrm{A} / \mathrm{O}=1.0$. After solvent extraction, the stripping 
was performed for three kinds of media $\left(\mathrm{HCl}, \mathrm{NH}_{3}\right.$ and $\mathrm{NaOH}$ aqueous solution) with different concentrations $(0.5,1.0,1.5$ and $3.0 \mathrm{~mol} / \mathrm{L})$. After stripping, in the second solvent extraction, the new aqueous phase containing $1.0 \times 10^{3} \mathrm{mg} \mathrm{L}^{-1} \mathrm{~W}(\mathrm{VI})$ was introduced into the organic phase with $\mathrm{A} / \mathrm{O}=1.0$. After the second solvent extraction, the second stripping was performed with the same conditions. Thus, the procedure for solvent extraction and stripping was repeatedly carried out for $5^{\text {th }}$ cycles. After the fifth continuous extraction-stripping procedure, the metal concentration in the organic phase for each cucle was determined by ICP-AES.

\section{Results and discussions}

\subsection{Pretreatment}

The AlCrN film coating on the WC-Co hard metal sample was gradually leached using the $\mathrm{H}_{2} \mathrm{SO}_{4}-\mathrm{H}_{3} \mathrm{PO}_{4}$ mixed acid medium. The surface morphology of the AlCrN film coating and the WC-Co sample after removal of the coating was analyzed by SEM, as shown in Figs. 3(a) and (b), respectively. The surface morphology before and after the removal treatment were completely different. The composition result evaluated by EDX was tabulated in Table $\mathbf{1}$ and we confirmed the complete removal of the AlCrN film coating.

After removal of the AlCrN film coating, the WC-Co sample was heated in an oxygen atmosphere at $1173 \mathrm{~K}$ for $10 \mathrm{~h}$. The XRD profiles of the WC-Co sample before and after oxidization are shown in Fig. 4. For the former, a sharp WC peak (00-025-1047) was detected, whereas for the latter, $\mathrm{WO}_{3}(01-083-0950)$ and $\mathrm{CoWO}_{4}(00-015-0867)$ peaks were clearly observed. Thus, we confirmed that the WC-Co sample was completely oxidized to generate $\mathrm{WO}_{3}$ and $\mathrm{CoWO}_{4}$.

\subsection{Leaching}

The leaching behavior of $\mathrm{W}$ present in the oxidized WC-Co sample was investigated and the amount of W leached by the $0.1 \mathrm{~mol} / \mathrm{L} \mathrm{LiOH}$ solution with respect to leaching time is shown in Fig. 5. The leaching reaction can be expressed as follows: 


$$
\mathrm{WO}_{3}+2 \mathrm{LiOH} \rightarrow \mathrm{WO}_{4}^{2-}+2 \mathrm{Li}^{+}+\mathrm{H}_{2} \mathrm{O}
$$

The amount of W leached in $500 \mathrm{~mL} 0.1 \mathrm{~mol} / \mathrm{L} \mathrm{LiOH}$ solution $\left(\mathrm{LiOH}: 5.0 \times 10^{-2} \mathrm{~mol}\right)$ gradually increased with leaching time and reached saturation at $7 \mathrm{~h}$. The $\mathrm{pH}$ value of the leaching solution gradually decreased with leaching time and reached a constant value at $7 \mathrm{~h}$. Finally, the saturated amount of $\mathrm{W}$ was $4.284 \mathrm{~g}\left(\mathrm{~W}: 2.33 \times 10^{-2} \mathrm{~mol}\right)$ and the final $\mathrm{pH}$ was 7.55 . Also, the molar stoichiometric ratio of $\mathrm{WO}_{3}: \mathrm{LiOH}$ was $1: 2.1$, which was consistent with that suggested by equation (4).

Furthermore, it is important to understand the distribution of tungstate ions in a wide $\mathrm{pH}$ range as listed in Table 2. It is known that $\left[\mathrm{WO}_{4}{ }^{2-}\right]$ is stable in alkaline solutions and reacts in acidic media based on the following equilibria:

$$
\begin{gathered}
{\left[\mathrm{WO}_{4}{ }^{2-}\right]+\mathrm{H}^{+} \Leftrightarrow\left[\mathrm{HWO}_{4}{ }^{-}\right], \log K_{1}=4.59} \\
{\left[\mathrm{WO}_{4}{ }^{2-}\right]+2 \mathrm{H}^{+} \Leftrightarrow\left[\mathrm{H}_{2} \mathrm{WO}_{4}\right], \log K_{2}=8.10} \\
6\left[\mathrm{WO}_{4}{ }^{2-}\right]+6 \mathrm{H}^{+} \Leftrightarrow\left[\mathrm{W}_{6} \mathrm{O}_{21}{ }^{6-}\right]+3 \mathrm{H}_{2} \mathrm{O}, \log K_{3}=52.5 \\
6\left[\mathrm{WO}_{4}{ }^{2-}\right]+7 \mathrm{H}^{+} \Leftrightarrow\left[\mathrm{HW}_{6} \mathrm{O}_{21}{ }^{5-}\right]+3 \mathrm{H}_{2} \mathrm{O}, \log K_{4}=59.98 \\
{\left[\mathrm{HW}_{6} \mathrm{O}_{21}{ }^{5-}\right]+2 \mathrm{H}^{+} \Leftrightarrow\left[\mathrm{H}_{3} \mathrm{~W}_{6} \mathrm{O}_{21}{ }^{3-}\right], \log K_{5}=9.72}
\end{gathered}
$$

According to the above equilibrium constants ( $\log K_{1}$ to $\log K_{5}$ ) (Sillen et. al., 1964), the distribution of tungstate ions was calculated as a function of pH, as shown in Fig. 6. This result indicated that the tungstate ions existed as the anionic species in the wide $\mathrm{pH}$ range. Therefore, amines would be effective to selectively extract these ions.

\subsection{Ion exchange}

The time dependence of the ion exchange is shown in Fig. 7. The saturated leaching solution including $\mathrm{W}(\mathrm{VI})$ and $\mathrm{Co}(\mathrm{II})$ indicates $\mathrm{pH}=7.55$ and this $\mathrm{pH}$ range is difficult to selectively extract 
$\mathrm{W}(\mathrm{VI})$ and $\mathrm{Co}(\mathrm{II})$ by solvent extraction process. As shown in Fig. 7, the ion exchange is smoothly proceeded to the reaction: $\mathrm{R}-\mathrm{SO}_{3} \mathrm{H}+\mathrm{Li}^{+} \rightarrow \mathrm{R}-\mathrm{SO}_{3} \mathrm{Li}+\mathrm{H}^{+}$. The alternation of $\mathrm{pH}$ was roughly proportional to the time of ion exchange. Then, as shown in Fig. 5, the complexation state of $\mathrm{W}(\mathrm{VI})$ ion is relatively dependent on the $\mathrm{pH}$ in an aqueous phase. Therefore, the aqueous phase with different $\mathrm{pH}$ conditions using the next solvent extraction was controlled by the time of ion exchange.

\subsection{Extraction behavior of $\mathrm{W}(\mathrm{VI})$ and $\mathrm{Co}(\mathrm{II})$}

The extraction behavior of $\mathrm{W}(\mathrm{VI})$ and $\mathrm{Co}(\mathrm{II})$ for $\left[\mathrm{R}_{3} \mathrm{~N}\right] /\left[\mathrm{P}_{2225}\right]\left[\mathrm{NTf}_{2}\right]$ or $\left[\mathrm{R}_{3} \mathrm{~N}\right] /$ kerosene system, $\mathrm{R}=\left(\mathrm{CH}_{2}\right)_{7} \mathrm{CH}_{3}$ in a wide $\mathrm{pH}$ range is shown in Figs. $8(\mathbf{a})$ or $\mathbf{8}(\mathbf{b})$, respectively. In the case of the $\left[\mathrm{R}_{3} \mathrm{~N}\right] /\left[\mathrm{P}_{2225}\right]\left[\mathrm{NTf}_{2}\right]$ system, the extraction percentage $(E)$ of $\mathrm{W}(\mathrm{VI})$ and $\mathrm{Co}(\mathrm{II})$ was $>95 \%$ and $<2.5 \%$ at $\mathrm{pH}=1.0$, respectively. This result indicated that $\mathrm{W}$ was selectively extracted at $\mathrm{pH}=1.0$ by the $\left[\mathrm{R}_{3} \mathrm{~N}\right] /\left[\mathrm{P}_{2225}\right]\left[\mathrm{NTf}_{2}\right]$ system. In addition, the extraction of $\mathrm{W}(\mathrm{VI})$ was dependent on the $\mathrm{pH}$ of the aqueous phase. This extraction tendency was consistent with previous results (Carvalho et. al., 1991, Coca et. al., 1990). Regarding W(VI) extraction, the ion association process can be expressed as follows:

$$
n\left[\mathrm{R}_{3} \mathrm{~N}\right]_{\text {org }}+\left[\mathrm{H}_{x} \mathrm{~W}_{y} \mathrm{O}_{z}{ }^{-}\right]_{\mathrm{aq}}+n\left[\mathrm{H}^{+}\right]_{\mathrm{aq}} \Leftrightarrow\left[\left(\mathrm{R}_{3} \mathrm{NH}\right)_{n} \mathrm{H}_{x} \mathrm{~W}_{y} \mathrm{O}_{z}\right]_{\mathrm{org}}
$$

where $x, y, z$, and $n$ are the stochiometric coefficients related to equation (10) and are highly dependent on the $\mathrm{pH}(\mathrm{Kim} \mathrm{T}$. K. et. al., 1968). From Fig. 6, for $\mathrm{pH}=1.0-4.5, \mathrm{pH}=4.5-7.0, \mathrm{pH}=$ 6.5-8.5 and $\mathrm{pH}=8.5-10.0$ in the aqueous phase, $\left[\mathrm{H}_{x} \mathrm{~W}_{y} \mathrm{O}_{z}{ }^{n-}\right]$ could be expressed as $\left[\mathrm{H}_{3} \mathrm{~W}_{6} \mathrm{O}_{21}{ }^{3-}\right](x$ $=3, y=6, z=21, n=3) ;\left[\mathrm{HW}_{6} \mathrm{O}_{21}{ }^{5-}\right](x=1, y=6, z=21, n=5) ;\left[\mathrm{W}_{6} \mathrm{O}_{21}{ }^{6-}\right](x=0, y=6, z=21, n=$ $6)$; and $\left[\mathrm{WO}_{4}{ }^{2-}\right](x=0, y=1, z=4, n=2)$, respectively. This reaction also indicated that the extraction yield of $\mathrm{W}(\mathrm{VI})$ rapidly decreased with increasing $\mathrm{pH}$. Moreover, the UV-Vis spectrum for $\left[\mathrm{H}_{x} \mathrm{~W}_{y} \mathrm{O}_{z}{ }^{n-}\right]$ or $\left[\left(\mathrm{R}_{3} \mathrm{NH}\right)_{n} \mathrm{H}_{x} \mathrm{~W}_{y} \mathrm{O}_{z}\right]$ was measured in aqueous or organic phase. As shown in Fig. 9, the shoulder peak at around $260 \mathrm{~nm}$ was observed in aqueous phase including $\left[\mathrm{H}_{x} \mathrm{~W}_{y} \mathrm{O}_{z}{ }^{n-}\right]$. This 
result was consistent with the reference (O. Glemser et. al., 1965). On the other hand, the sharp peak at around $322 \mathrm{~nm}$ was observed in the organic phase. We conjectured that this peak would be related with the extracted $\left[\left(\mathrm{R}_{3} \mathrm{NH}\right)_{n} \mathrm{H}_{x} \mathrm{~W}_{y} \mathrm{O}_{z}\right]$ complex. The separation factor of W/Co in $\left[\mathrm{R}_{3} \mathrm{~N}\right] /\left[\mathrm{P}_{2225}\right]\left[\mathrm{NTf}_{2}\right]$ or $\left[\mathrm{R}_{3} \mathrm{~N}\right] /$ kerosene system was summarized in Table 3. As shown in Table 3, the separation factor of $\mathrm{W} / \mathrm{Co}$ in $\left[\mathrm{R}_{3} \mathrm{~N}\right] /\left[\mathrm{P}_{2225}\right]\left[\mathrm{NTf}_{2}\right]$ system is relatively larger than that in $\left[\mathrm{R}_{3} \mathrm{~N}\right] /$ kerosene. As a result, the IL with high dielectric constant would be useful for the separation of $\mathrm{W}(\mathrm{VI})$ and $\mathrm{Co}(\mathrm{II})$ for the comparison of the conventional organic solvent. Moreover, the neutralization of the acidic solution after solvent extraction of $\mathrm{W}(\mathrm{VI})$ did not produce any detectable precipitate.

After the removal of W(VI) by solvent extraction (I), the extraction behavior and slope analysis of Co(II) by PC-88A is shown in Figs. 10(a) and 10(b), respectively. From the slope analysis, the slope between $\log D$ and $\mathrm{pH}$ was 1.90 , which indicated that the stoichiometry ratio of Co(II):PC-88A was 1:2. PC-88A is usually thought to be a weak organic acid that can extract metallic ions by cation exchange reactions. The equilibrium for the extraction of $\mathrm{Co}$ (II) from the acidic medium using PC-88A can be generalized as follows (Jayachandran et. al., 1999):

$$
\left[\mathrm{Co}^{2+}\right]_{\mathrm{aq}}+2\left[(\mathrm{HL})_{2}\right]_{\mathrm{org}} \Leftrightarrow\left[\mathrm{CoL}_{2} \cdot 2 \mathrm{HL}\right]_{\mathrm{org}}+2\left[\mathrm{H}^{+}\right]_{\mathrm{aq}}
$$

where $\mathrm{HL}=\left(\mathrm{H}_{17} \mathrm{C}_{8}\right) \mathrm{P}\left(\mathrm{OC}_{8} \mathrm{H}_{17}\right) \mathrm{O}(\mathrm{OH})$ and $(\mathrm{HL})_{2}=$ dimeric form of PC-88A in the organic phase. It is generally accepted that PC-88A is dimeric in low-polarity solvents (Marcus et. al., 1969). The extraction yield of $\mathrm{Co}$ (II) increased with increasing $\mathrm{pH}$ and the extraction percentage was $>95 \%$ at $\mathrm{pH}>4.3$.

\subsection{Reuse of organic solvent for extraction-electrodeposition \\ Finally, we investigated the reuse of the $\mathrm{W}(\mathrm{VI})$ in $\left[\mathrm{R}_{3} \mathrm{~N}\right] /\left[\mathrm{P}_{2225}\right]\left[\mathrm{NTf}_{2}\right], \mathrm{R}=\left(\mathrm{CH}_{2}\right)_{7} \mathrm{CH}_{3}$ solvent for continuous solvent extraction and stripping. A series of results for solvent extraction and stripping over five cycles was summarized in Table 4 . In the 1 st -5 th cycles of the solvent}


extraction process, the extraction percentage of $\mathrm{W}(\mathrm{VI})$ with $\left[\mathrm{R}_{3} \mathrm{~N}\right] /\left[\mathrm{P}_{2225}\right]\left[\mathrm{NTf}_{2}\right]$ was maintained to be high $(90.8-97.6 \%)$. On the other hand, $\mathrm{NaOH}(0.5-1.0 \mathrm{~mol} / \mathrm{L}) \mathrm{NH}_{3}(1.0 \mathrm{~mol} / \mathrm{L})$ base media were found most successful reagents, although acid medium was unsuccessful due to the stability of $\mathrm{W}(\mathrm{VI})$ complex with back extraction media. Then, $\mathrm{NH}_{3}$ solution was preferred to $\mathrm{NaOH}$ solution, because it was easier to produce ammonium paratungstate (APT), which is usually the final form required by the tungsten industry. This result indicated that the extraction efficiency of the TOA extractant was high, and $\left[\mathrm{R}_{3} \mathrm{~N}\right] /\left[\mathrm{P}_{2225}\right]\left[\mathrm{NTf}_{2}\right]$ could repeatedly be used for extraction-stripping process.

\section{Conclusion}

We demonstrated a novel hydrometallurgical process to effectively separate $\mathrm{W}$ and Co from WC-Co hard metal. This process involved the following steps: pretreatment, leaching, ion exchange, and two-step solvent extraction (I and II) using ionic liquids (ILs). First, the AlCrN film coating was completely removed from the WC-Co hard metal surface by leaching in a $\mathrm{H}_{2} \mathrm{SO}_{4}-\mathrm{H}_{3} \mathrm{PO}_{4}$ mixed acid system. Then, oxidization of the WC-Co hard metal was conducted at $1173 \mathrm{~K}$ for $10 \mathrm{~h}$ to form $\mathrm{WO}_{3}$ and $\mathrm{CoWO}_{4}$ powders, as confirmed by XRD. After the oxidization process, the leaching reaction $\mathrm{WO}_{3}+2 \mathrm{LiOH} \rightarrow \mathrm{WO}_{4}{ }^{2-}+2 \mathrm{Li}^{+}+\mathrm{H}_{2} \mathrm{O}$ proceeded and the stoichiometry of $\mathrm{WO}_{3}: \mathrm{LiOH}$ was $1: 2.1$, which was consistent with that of the leaching reaction. It was beneficial to exchange $\mathrm{H}^{+}$and $\mathrm{Li}^{+}$in the leaching solution by a cation exchange resin after the leaching process.

A two-step solvent extraction process using ILs was employed to separate W(VI) and Co(II). For solvent extraction (I), the $\mathrm{IL}\left[\mathrm{P}_{2225}\right]\left[\mathrm{NTf}_{2}\right]$ with TOA as the extractant selectively separated $\mathrm{W}(\mathrm{VI})$. The extraction mechanism of $\mathrm{W}(\mathrm{VI})$ using the $\left[\mathrm{R}_{3} \mathrm{~N}\right] /\left[\mathrm{P}_{2225}\right]\left[\mathrm{NTf}_{2}\right], \mathrm{R}=\left(\mathrm{CH}_{2}\right)_{7} \mathrm{CH}_{3}$ system was based on the ion association reaction $n\left[\mathrm{R}_{3} \mathrm{~N}\right]_{\text {org }}+\left[\mathrm{H}_{x} \mathrm{~W}_{y} \mathrm{O}_{z}{ }^{n-}\right]_{\mathrm{aq}}+n\left[\mathrm{H}^{+}\right]_{\mathrm{aq}} \Leftrightarrow$

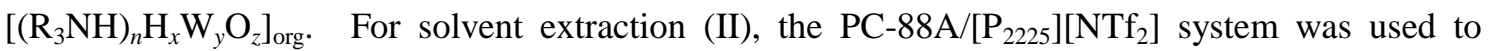
extract $\mathrm{Co}$ (II). Based on the slope analysis, the extraction mechanism was revealed to be based on the cation exchange reaction $\left[\mathrm{Co}^{2+}\right]_{\mathrm{aq}}+2\left[(\mathrm{HL})_{2}\right]_{\mathrm{org}} \Leftrightarrow\left[\mathrm{CoL}_{2} \cdot 2 \mathrm{HL}\right]_{\mathrm{org}}+2\left[\mathrm{H}^{+}\right]_{\mathrm{aq}} . \quad$ A novel 
hydrometallurgical process was allowed us to conclude that it was effective to separate $\mathrm{W}(\mathrm{VI})$ and $\mathrm{Co}$ (II) from WC-Co hard metal wastes by leaching, ion exchange and solvent extraction with $\left[\mathrm{R}_{3} \mathrm{~N}\right] /\left[\mathrm{P}_{2225}\right]\left[\mathrm{NTf}_{2}\right]$ system, $\mathrm{R}=\left(\mathrm{CH}_{2}\right)_{7} \mathrm{CH}_{3}$. Finally, the reuse availability of $\mathrm{W}(\mathrm{VI})$ in $\left[\mathrm{R}_{3} \mathrm{~N}\right] /\left[\mathrm{P}_{2225}\right]\left[\mathrm{NTf}_{2}\right]$ solvent was investigated by continuous extraction and stripping process. In the 1st-5th cycles on solvent extraction, the extraction percentage of $\mathrm{W}(\mathrm{VI})$ kept high performance (90.8-97.6\%). Then, $\mathrm{NaOH}(0.5-1.0 \mathrm{~mol} / \mathrm{L}) \mathrm{NH}_{3}(1.0 \mathrm{~mol} / \mathrm{L})$ base media was maintained high value (80.1-90.2\%). This series of experimental results allowed us to conclude that $\left[\mathrm{R}_{3} \mathrm{~N}\right] /\left[\mathrm{P}_{2225}\right]\left[\mathrm{NTf}_{2}\right]$ solvent can be recycled from solvent extraction and stripping process.

\section{References}

Brookes K. J. A., 1996. World Directory and Handbook of Hardmetals and Hard Materials, Sixth ed. International Carbide Data, Hertfordshire.

Carvalho R. A. G., Sampaio, M. N. M., 1991. Solvent extraction of tungsten by alkylamines-hydrochloric acid and alkylamines-sulphuric acid, Hydrometallurgy, 26, 137-150.

Chim Y. C., Ding X. Z., Zeng X. T., Zhang S., 2009. Oxidation resistance of TiN, CrN, TiAlN and CrAlN coatings deposited by lateral rotating cathode arc, Thin Solid Films, 517(17), 4845-4849.

Coca J., Diez F. V., Moris M. A., 1990. Solvent extraction of molybdenum and tungsten by Alamine 336 and DEHPA, Hydrometallurgy, 25, 125-135.

Gaur Singh R. P., 2006. Modern hydrometallurgical production methods for tungsten. JOM pp.45.

Lassner E., 1995. From tungsten concentrates and scrap to highly pure ammonium paratungstate (APT), Int. J. Refract. Met. Hard Mater., 13, 35-44.

Gerhardt N. I., Palant A. A., Petrova V. A., Tagirov R. K., 2001. Solvent extraction of molybdenum (VI), tungsten (VI) and rhenium(VII) by diisododecylamine from leach liquors, Hydrometallurgy, 60, $1-5$.

Glemser O., Holznagel W., Höltje W., Sohwarzmann E., 1965. Untersuchungen über Isopolywolframate, Z. Naturforschung, 20b, 725-746.

Gu W.-H., Jeong Y. S., Kim K., Kim J.-C., Son S.-H., Kim S., 2012. Thermal oxidation behavior of 
WC-Co hard metal machining tool tip scraps, J. Mater. Process. Technol., 212, 1250-1256.

Jayachandran J., Dhadke P. M., 1999. Solvent extraction separation of cobalt(II) with 2-ethylhexyl phosphonic acid mono-2-ethylhexyl ester (PC-88A), Chem. Anal., 44, 157-165.

Kim T. K., Mooney R. W., Chiola V., 1968. Study of soluble tungstate species by solvent extraction, Sep. Sci. Technol., 3(5), 467-478.

Lide D. R., 1993. CRC Handbook of Chemistry and Physics, New York.

Marcus Y., Kertes A. S., 1969. Ion Exchange and Solvent Extraction of Metal Complexes, Wiley-Interscience, London, p.528.

Palant A. A., Latsenko N. A., Petrova V. A., 1998. Solvent extraction of molybdenum (VI) by diisododecylamine from sulphuric acid solution, Hydrometallurgy, 48, 83-90.

Pandey B. D., Kumar V., Bagchi D., Jana R. K., 2001. Processing of tungsten pre-concentrate from low grade ore to recover metallic values, Miner. Process. Extr. Metall. Rev., 22, 101-120.

Sato T., Sato K., 1995. Liquid-liquid extraction of tungsten (VI) from hydrochloric acid solutions by neutral organophosphorus compounds and high molecular weight amines, Hydrometallurgy, 37, 253-266.

Sillen L. G., Martell A. E., 1964. Stability constants of metal-ion complexes section 1, 97.

Tsunashima K., Ono Y., Sugiya M., 2011. Functionalized ionic liquids as electrolytes for lithium-ion batteries, Electrochim. Acta, 56, 4351-4355.

Tsunashima K., Sugiya M., 2007. Physical and electrochemical properties of low-viscosity ionic liquids as potential electrolytes, Electrochem. Commun., 9, 2353-2358.

Zhang P., Inoue K., Yoshizuka K., Tsuyama H., 1996. Extraction and selective stripping of molybdenum (VI) and vanadium (IV) from sulfuric acid solution containing aluminum (III), cobalt (II), nickel (II) and iron (III) by LIX 63 in Exxsol D80, Hydrometallurgy, 41, 43-53. 


\section{Caption of Figures}

Fig. 1 A novel hydrometallurgical process using ionic liquid for the separation of W(VI) and Co(II) from WC-Co hard metal wastes.

Fig. 2 Molecular structure of (A) triethyl-pentyl-phosphonium cation $\left(\mathrm{P}_{2225}{ }^{+}\right)$and (B) bis(trifluoro methyl-sulfonyl)amide anion $\left(\mathrm{NTf}_{2}{ }^{-}\right)$.

Fig. 3 SEM image of (a)AlCrN coating film on WC-Co hard metal wastes and (b) WC-Co hard metal wastes after removal of AlCrN coating film.

Fig. 4 XRD profile of WC-Co hard metal wastes and oxidized WC-Co sample at $1173 \mathrm{~K}$ for $10 \mathrm{~h}$.

Fig. 5 Leaching behavior of W(VI) from oxidized WC-Co sample in $0.1 \mathrm{~mol} / \mathrm{L} \mathrm{LiOH}$ at $343 \mathrm{~K}$ for $19 \mathrm{~h}$.

๑: W leached, $\square: \mathrm{pH}$

Fig. 6 Relationship between distribution of various tungstate ions and $\mathrm{pH}$ calculated by equilibration constants from $\log K_{1}$ to $\log K_{5}$.

Red line: $\left[\mathrm{H}_{3} \mathrm{~W}_{6} \mathrm{O}_{21}{ }^{3-}\right]$, orange line: $\left[\mathrm{HW}_{6} \mathrm{O}_{21}{ }^{5-}\right]$, green line: $\left[\mathrm{W}_{6} \mathrm{O}_{21}{ }^{6-}\right]$, blue line: $\left[\mathrm{WO}_{4}{ }^{2-}\right]$ and purple line: $\left[\mathrm{HWO}_{4}^{-}\right],\left[\mathrm{H}_{2} \mathrm{WO}_{4}\right]$

Fig. 7 Relationship between the time of ion exchange and $\mathrm{pH}$ in aqueous phase.

Fig. 8 Extraction behavior of $\mathrm{W}(\mathrm{VI})$ and $\mathrm{Co}(\mathrm{II})$ (a) $\left[\mathrm{P}_{2225}\right]\left[\mathrm{NTf}_{2}\right]$ and (b) kerosene by solvent extraction on $\left[\mathrm{R}_{3} \mathrm{~N}\right] /\left[\mathrm{P}_{2225}\right]\left[\mathrm{NTf}_{2}\right], \mathrm{R}=\left(\mathrm{CH}_{2}\right)_{7} \mathrm{CH}_{3}$ system after ion exchange. red circle: $\mathrm{W}(\mathrm{VI})$ for aqueous phase including $\left[\mathrm{H}_{3} \mathrm{~W}_{6} \mathrm{O}_{21}{ }^{3-}\right]$, brown circle: $\mathrm{W}(\mathrm{VI})$ for aqueous phase including $\left[\mathrm{HW}_{6} \mathrm{O}_{21}{ }^{5-}\right]$, rectangle: $\mathrm{Co}(\mathrm{II})$

Fig. 9 UV-Vis spectrum for each W(VI) complex in aqueous or organic phase.

solid line: $\left[\mathrm{H}_{x} \mathrm{~W}_{y} \mathrm{O}_{z}{ }^{n-}\right]$ in aqueous phase, dotted line: extracted $\left[\left(\mathrm{R}_{3} \mathrm{NH}\right)_{n} \mathrm{H}_{x} \mathrm{~W}_{y} \mathrm{O}_{z}\right]$ in organic phase

Fig. 10 (a) Extraction behavior of Co(II) by solvent extraction on PC-88A/[ $\left.\mathrm{P}_{2225}\right]\left[\mathrm{NTf}_{2}\right]$ system 
and (b) slope analysis after removal of W(VI).

Fig.1
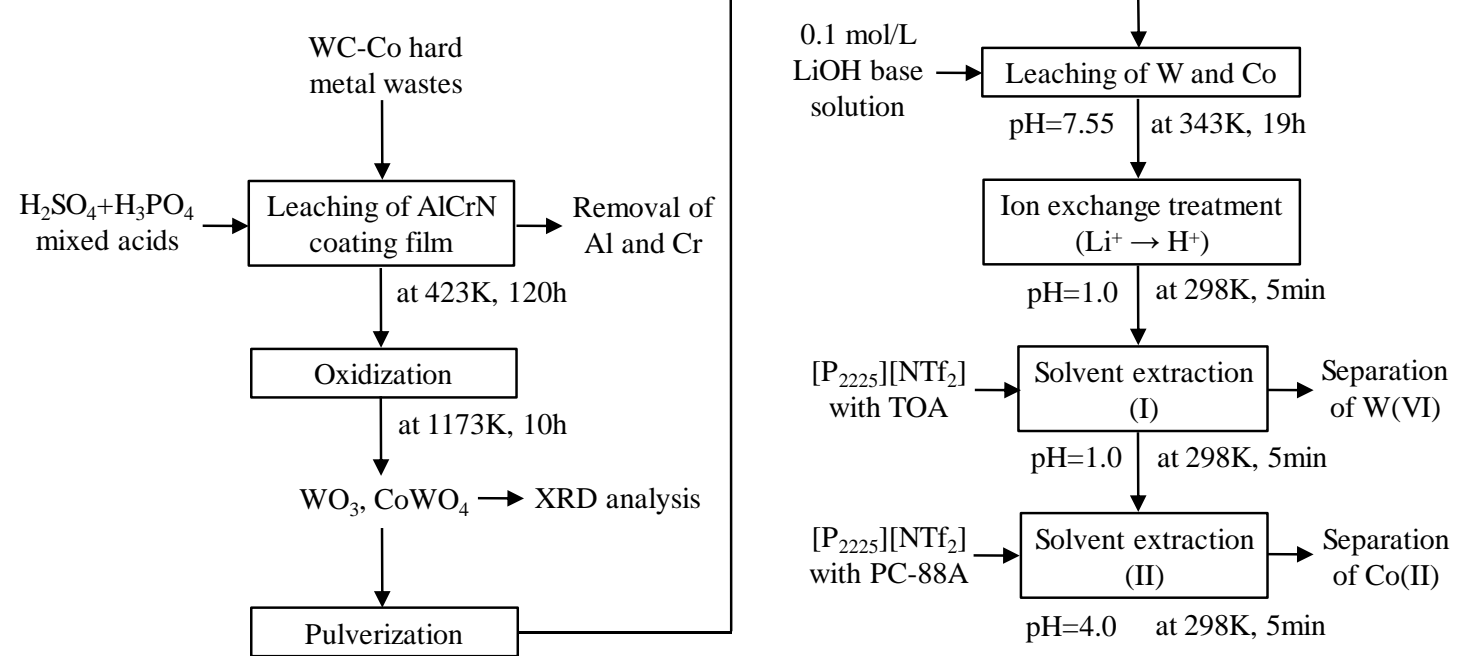
Fig. 2 
(A)

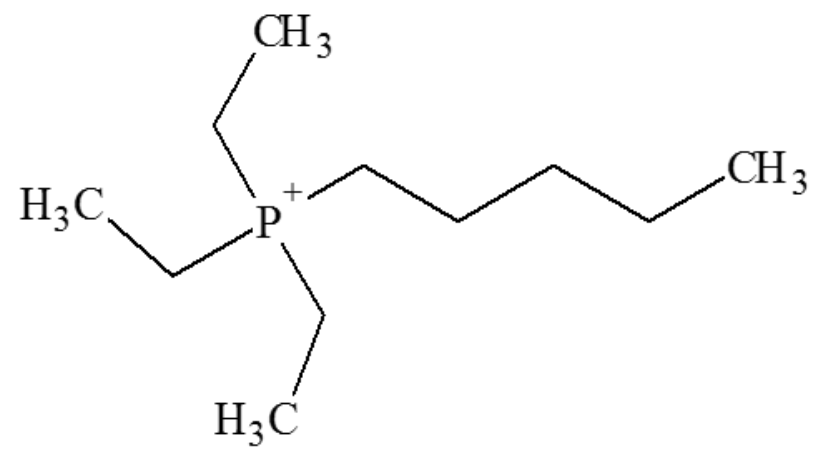

(B)

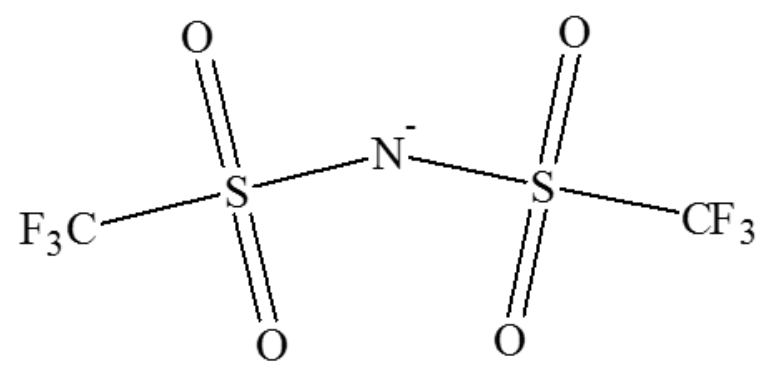

Fig. 3 


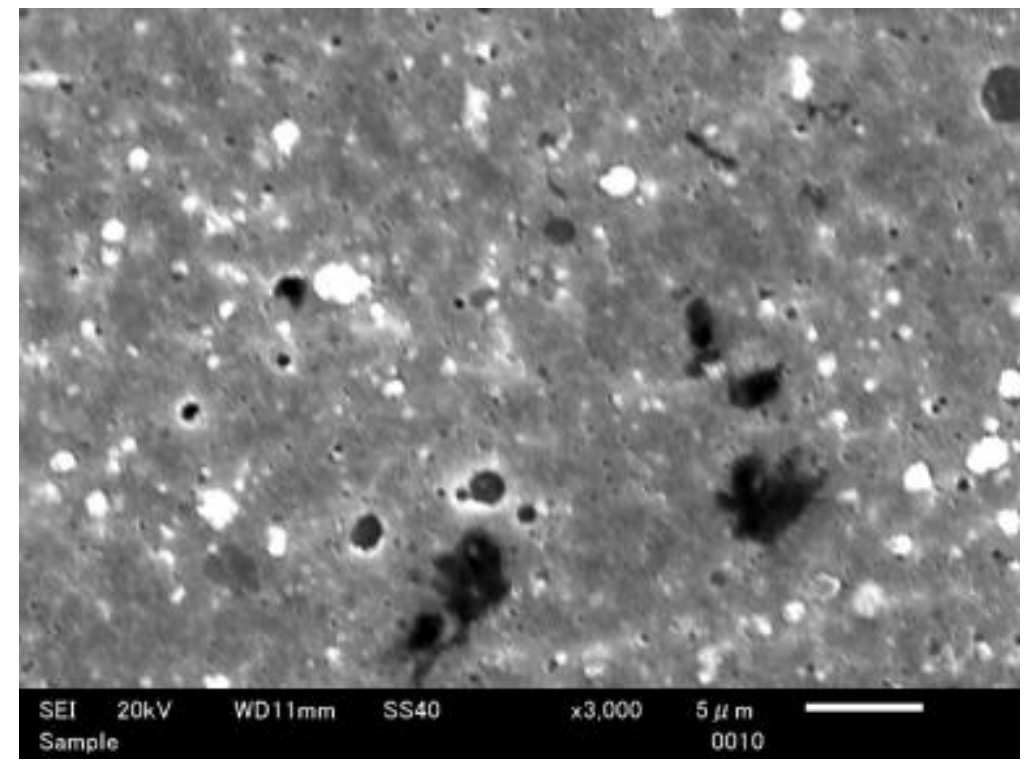

(a) AlCrN coating film on WC-Co hard metal

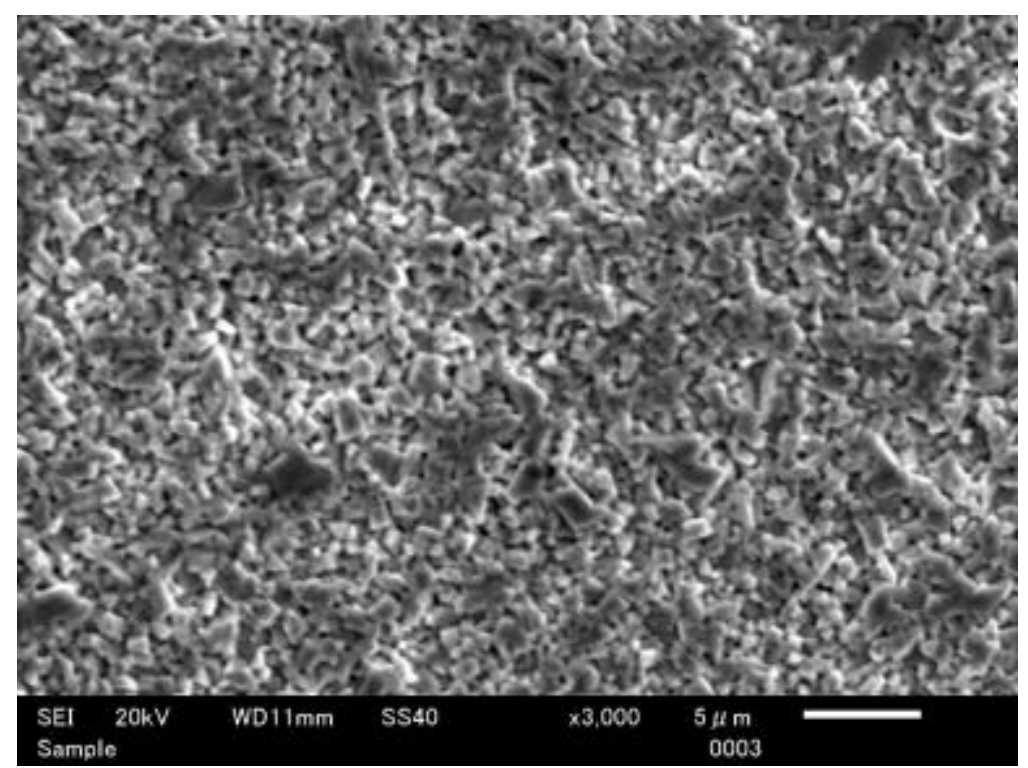

(b) WC-Co hard metal after removal of AlCrN coating film

Fig. 4 


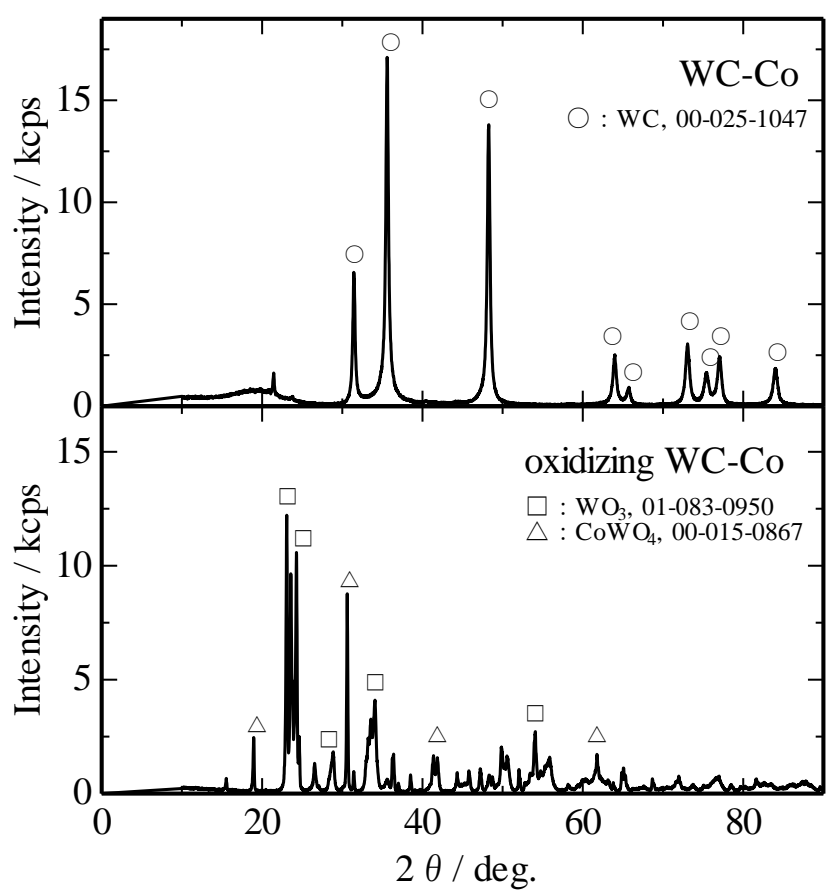

Fig. 5 


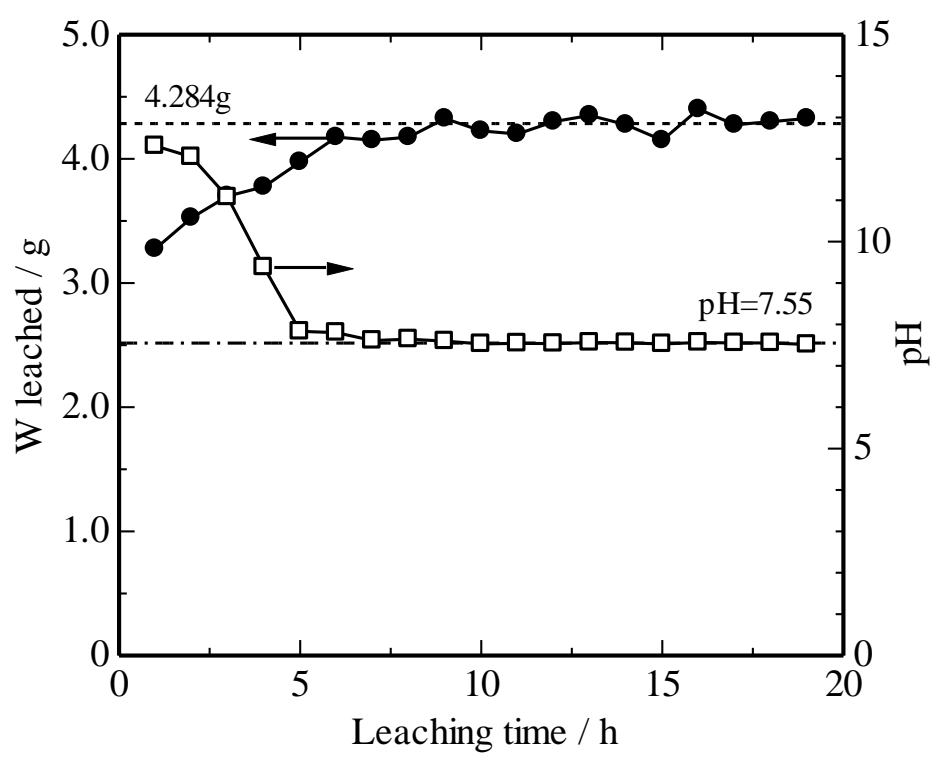

Fig. 6 


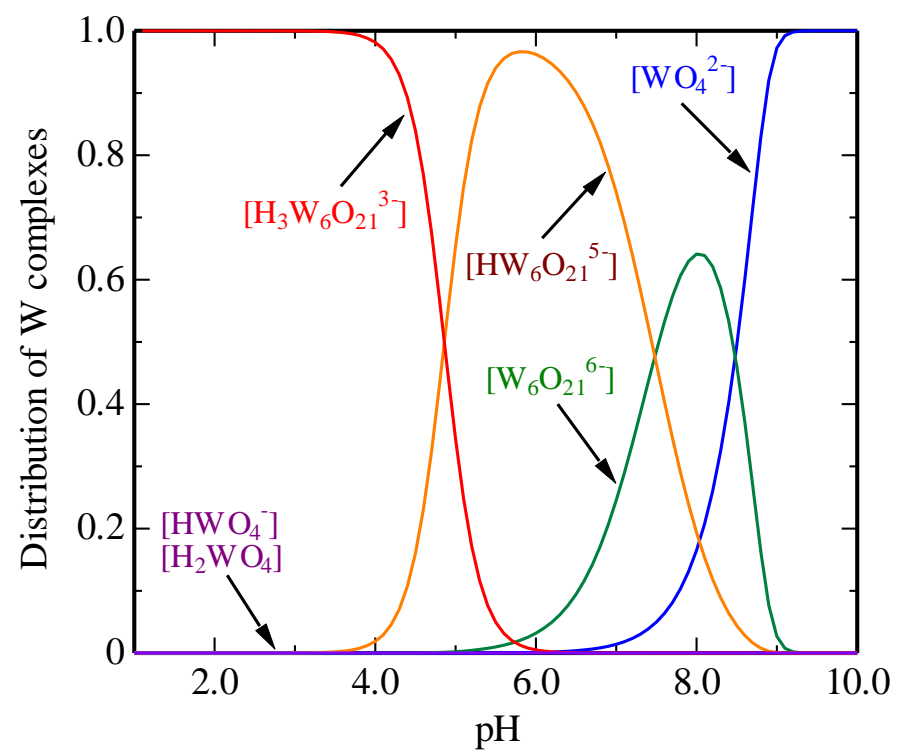

Fig. 7 


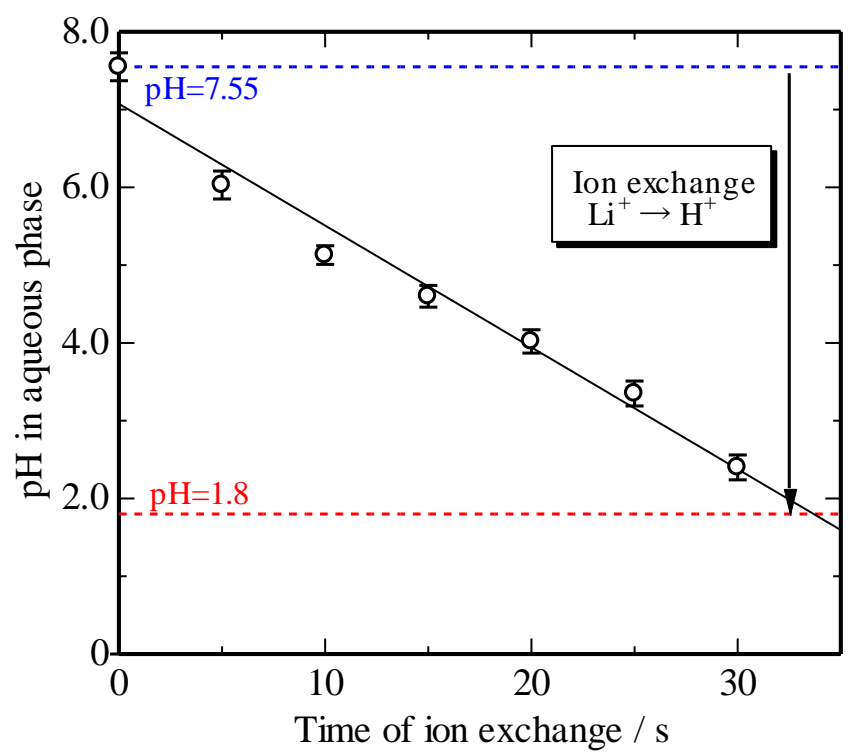

Fig. 8 

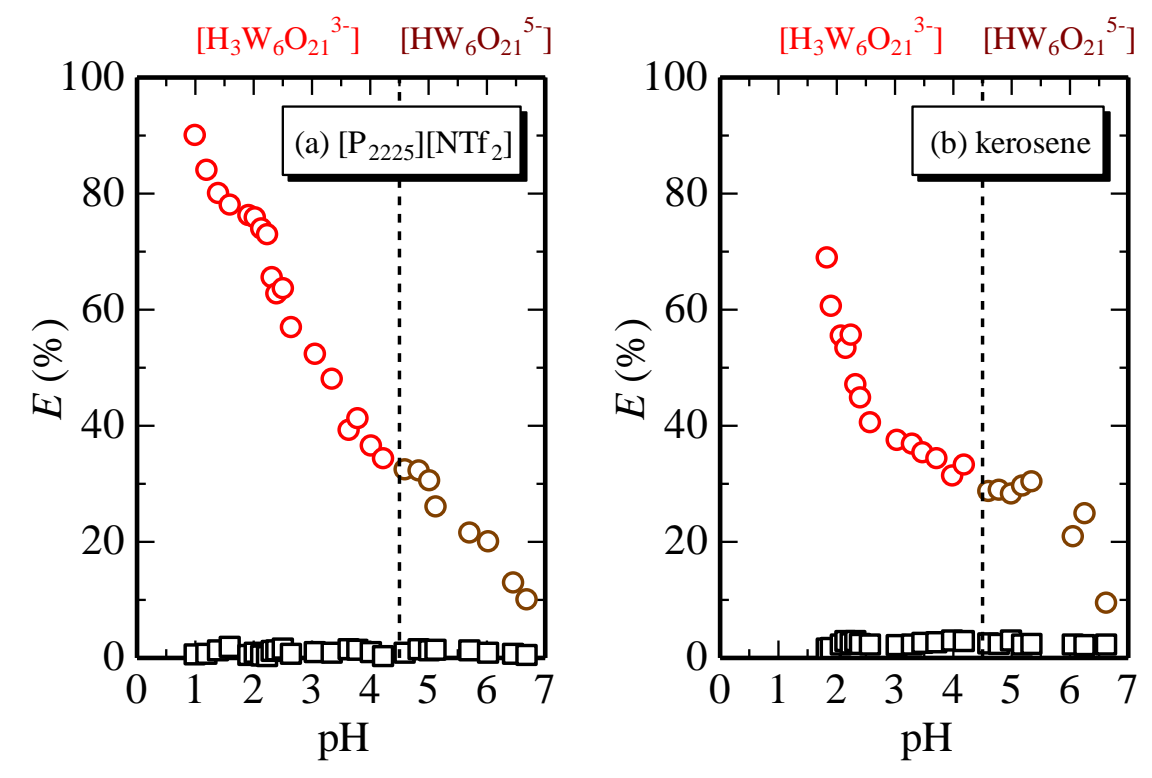

Fig. 9 


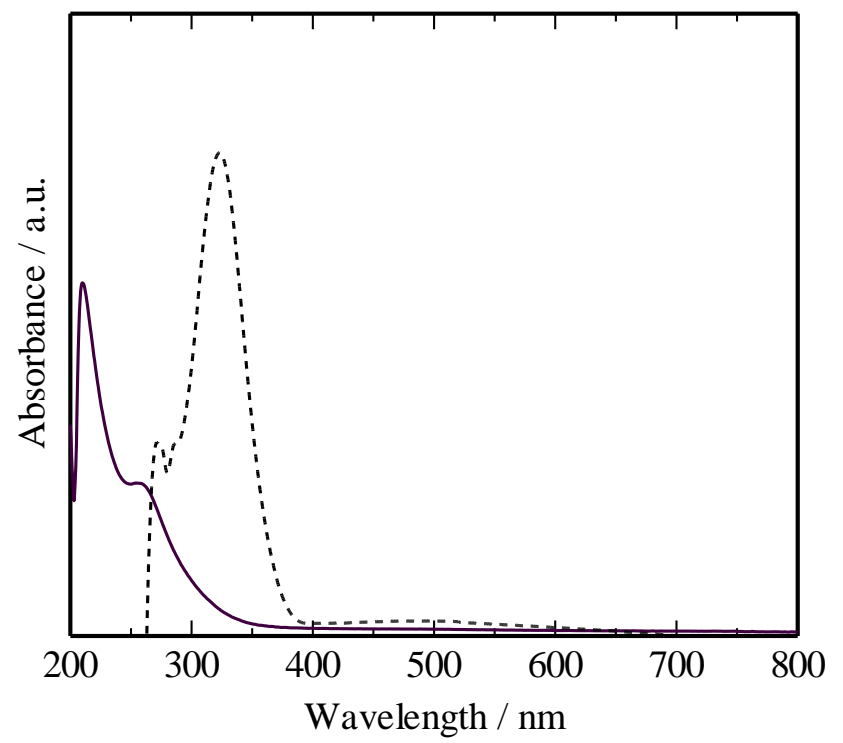

Fig.10 

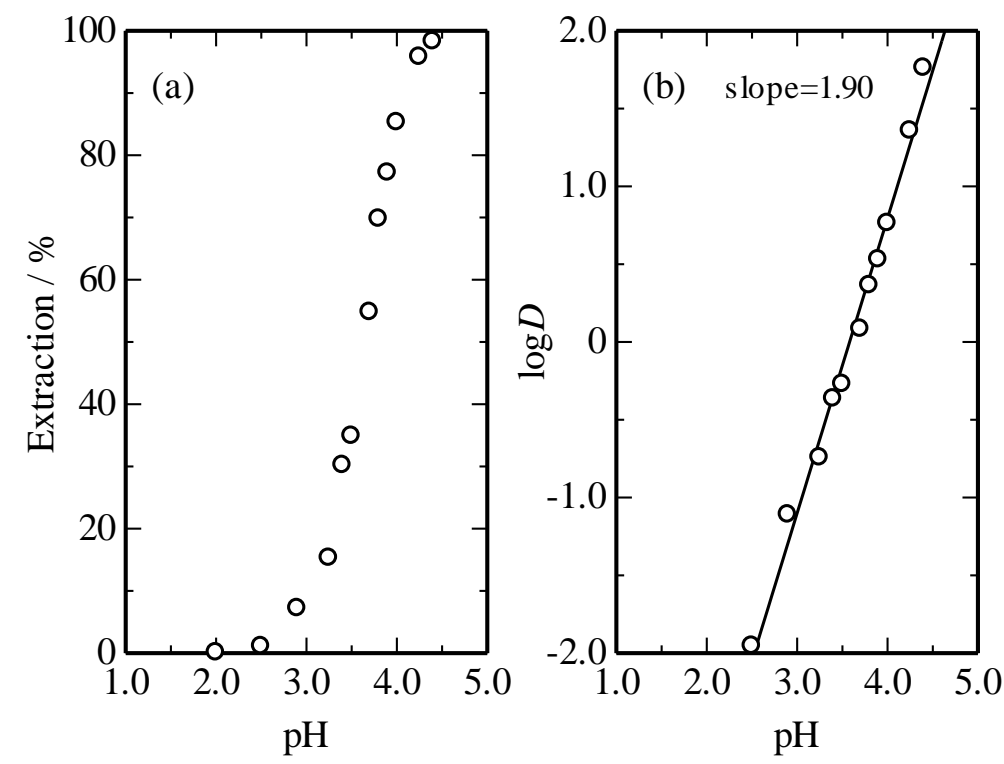
Table 1 Weight composition (wt.\%) of AlCrN coating film and WC-Co hard metal by EDX analysis

\begin{tabular}{lccccccc}
\hline & $\mathrm{Al}$ & $\mathrm{Si}$ & $\mathrm{Ti}$ & $\mathrm{Cr}$ & $\mathrm{Co}$ & $\mathrm{Y}$ & $\mathrm{W}$ \\
\hline AlCrN coating film & 47.67 & 0.10 & 0.11 & 51.72 & 0.13 & 0.08 & 0.18 \\
WC-Co hard metal & 0.09 & 3.05 & 0.55 & 0.03 & 0.47 & 0.85 & 94.96 \\
\hline
\end{tabular}


Table 2 Polytungstates and their relation to the $\mathrm{pH}$ of the aqueous medium.

\begin{tabular}{ccc}
\hline $\mathrm{pH}$ & Ionic species & $y / n$ \\
$1.0-4.5$ & {$\left[\mathrm{H}_{3} \mathrm{~W}_{6} \mathrm{O}_{21}{ }^{3-}\right]$ (pseudo meta-tungstate) } & 2.0 \\
$4.5-7.0$ & {$\left[\mathrm{HW}_{6} \mathrm{O}_{21}{ }^{5-}\right]$ (para-tungstate) } & 1.2 \\
$6.5-8.5$ & {$\left[\mathrm{~W}_{6} \mathrm{O}_{21}{ }^{6-}\right]$} & 1.0 \\
$8.5-10.0$ & {$\left[\mathrm{WO}_{4}{ }^{2-}\right]$} & 0.5 \\
\hline
\end{tabular}


Table 3 Separation factor of $\mathrm{W}(\mathrm{VI})$ and $\mathrm{Co}(\mathrm{II})$ for $\left[\mathrm{R}_{3} \mathrm{~N}\right] /\left[\mathrm{P}_{2225}\right]\left[\mathrm{NTf}_{2}\right]$ or $\left[\mathrm{R}_{3} \mathrm{~N}\right] /$ kerosene system, $\mathrm{R}=\left(\mathrm{CH}_{2}\right)_{7} \mathrm{CH}_{3}$.

\begin{tabular}{cccc}
\hline $\mathrm{pH}$ & $\mathrm{W} / \mathrm{Co}$ in $\left[\mathrm{P}_{2225}\right]\left[\mathrm{NTf}_{2}\right]$ & $\mathrm{pH}$ & W/Co in kerosene \\
\hline 1.92 & 797.2 & 1.91 & 135.0 \\
2.32 & 170.7 & 2.33 & 44.1 \\
3.35 & 114.5 & 3.30 & 37.0 \\
4.02 & 63.3 & 3.99 & 21.8 \\
5.02 & 36.1 & 5.00 & 18.8 \\
6.03 & 31.0 & 6.06 & 16.8 \\
6.69 & 27.7 & 6.63 & 6.6 \\
\hline
\end{tabular}


Table 4 A series of results of W(VI) for solvent extraction and stripping process at fifth cycles.

\begin{tabular}{|c|c|c|c|c|c|}
\hline & Solvent extraction & Stripping & & & \\
\hline & {$\left[\mathrm{R}_{3} \mathrm{~N}\right] /\left[\mathrm{P}_{2225}\right]\left[\mathrm{NTf}_{2}\right]$} & Molarity & $\mathrm{HCl}$ & $\mathrm{NH}_{3}$ & \\
\hline No. & $E /(\%)$ & $(\mathrm{mol} / \mathrm{L})$ & $E /(\%)$ & $E /(\%)$ & $E /(\%)$ \\
\hline \multirow[t]{4}{*}{$1^{\mathrm{st}}$} & 97.6 & 0.5 & 29.8 & 61.4 & 89.8 \\
\hline & & 1.0 & 19.1 & 85.3 & 86.7 \\
\hline & & 1.5 & 13.2 & 74.2 & 75.1 \\
\hline & & 3.0 & 12.1 & 51.6 & 71.2 \\
\hline \multirow[t]{4}{*}{$2^{\text {nd }}$} & 94.8 & 0.5 & 18.2 & 69.2 & 81.6 \\
\hline & & 1.0 & 13.8 & 86.8 & 84.3 \\
\hline & & 1.5 & 12.5 & 73.6 & 75.4 \\
\hline & & 3.0 & 10.6 & 41.5 & 70.2 \\
\hline \multirow[t]{4}{*}{$3^{\text {rd }}$} & 93.2 & 0.5 & 16.1 & 68.9 & 80.3 \\
\hline & & 1.0 & 12.4 & 87.2 & 82.6 \\
\hline & & 1.5 & 10.3 & 77.8 & 71.6 \\
\hline & & 3.0 & 9.6 & 35.6 & 69.8 \\
\hline \multirow[t]{4}{*}{$4^{\text {th }}$} & 91.6 & 0.5 & 13.2 & 70.3 & 81.8 \\
\hline & & 1.0 & 11.6 & 89.2 & 80.9 \\
\hline & & 1.5 & 7.8 & 78.4 & 70.4 \\
\hline & & 3.0 & 8.2 & 40.6 & 65.2 \\
\hline \multirow[t]{4}{*}{$5^{\text {th }}$} & 90.8 & 0.5 & 12.6 & 73.4 & 80.4 \\
\hline & & 1.0 & 10.3 & 90.2 & 80.1 \\
\hline & & 1.5 & 6.9 & 74.1 & 65.8 \\
\hline & & 3.0 & 7.1 & 32.8 & 62.4 \\
\hline
\end{tabular}

